\title{
Costs of Health IT: Beginning to Understand the Financial Impact of a Dental School EHR
}

\author{
Heiko Spallek, D.M.D., Ph.D., M.S.B.A. (CIS); Lynn Johnson, Ph.D.; Joseph Kerr, M.B.A., \\ P.M.P.; David Rankin, M.S., PGCertIA, CGCIO, ITIL, CCNA, MCSE, CNE \\ Abstract: Health Information Technology (Health IT) constitutes an integral component of the operations of most academic \\ dental institutions nowadays. However, the expenses associated with the acquisition and the ongoing maintenance of these \\ complex systems have often been buried among costs for other electronic infrastructure systems, distributed across various cost \\ centers including unmeasured central campus support, covered centrally and therefore difficult to quantify, and spread over years, \\ denying school administrators a clear understanding of the resources that have been dedicated to Health IT. The aim of this study \\ was to understand the financial impact of Health IT at four similar U.S. dental schools: two schools using a purchased Electronic \\ Health Record (EHR), and two schools that developed their own EHR. For these schools, the costs of creating (\$2.5 million) \\ and sustaining $(\$ 174,000)$ custom EHR software were significantly higher than acquiring $(\$ 500,000)$ and sustaining $(\$ 121,000)$ \\ purchased software. These results are based on historical data and should not be regarded as a gold standard for what a complete \\ Health IT suite should cost. The presented data are intended to inform school administrators about the myriad of costs associated \\ with Health IT and give them a point of reference when comparing costs or making estimates for implementation projects.
}

Dr. Spallek is Associate Professor, Dental Public Health, Center for Informatics in Oral Health Translational Research and Associate Dean, Office of Faculty Affairs, School of Dental Medicine, University of Pittsburgh; Dr. Johnson is Professor of Dentistry, School of Dentistry, Associate Dean for Faculty Affairs and Institutional Effectiveness, and Clinical Professor, School of Information, University of Michigan; Mr. Kerr is Associate Dean for Administration, School of Dental Medicine, University at Buffalo; and Mr. Rankin is Director, Office of Computing and Information Systems, School of Dentistry, University of North Carolina at Chapel Hill. Direct correspondence and requests for reprints to Dr. Heiko Spallek, School of Dental Medicine, University of Pittsburgh, 427 Salk Hall, 3501 Terrace Street, Pittsburgh, PA 15261; 412-648-8882; hspallek@pitt.edu.

Keywords: dental education, dental school clinics, information technology, Health IT, electronic health record, electronic patient record, dental informatics, information systems

Submitted for publication 9/11/13; accepted 1/24/14

$\mathrm{H}$ ealth Information Technology (Health IT) has evolved into a vital component of the dental education infrastructure, yet few administrators understand the financial impact of their school's Health IT infrastructure, which includes hardware and software acquisition and operating costs $^{1}$ related to the Electronic Health Record (EHR). EHR advocates have long claimed EHR systems will lead to cost savings, reduce medical errors, and improve health. ${ }^{2}$ EHR opponents, on the other hand, lament that after much effort and expenses there is little to show in terms of improved patient outcomes. ${ }^{3,4}$ Dental schools began introducing EHRs in the 1990s and fully embraced them a decade later, mostly driven by the desire to have clinical information readily available whether for patient care, research, or quality assurance. Nowadays, the majority of U.S. dental schools consider their EHRs pivotal to patient safety as they provide information for patient care, ensure fiscal accountability, track quality of patient care, manage clinic operations, and report student work among other tasks ${ }^{5}$ serving various stakeholders (Figure 1). Health care reform efforts ${ }^{6}$ and federal mandates ${ }^{7}$ require improved communication among all health care providers, improved care coordination across disciplines, and patient access to information. To accomplish these goals, new investments will need to be made for schools' Health IT infrastructure. Yet most schools do not track costs associated with the investment that has been made in their current Health IT infrastructure, let alone estimate the cost of future improvements.

The aim of our study was to summarize the financial lessons that have been learned regarding Health IT infrastructure, with the EHR as its central component, at four similar U.S. dental schools: two schools using a purchased EHR, and two schools that developed their own EHR. (Three of four schools 


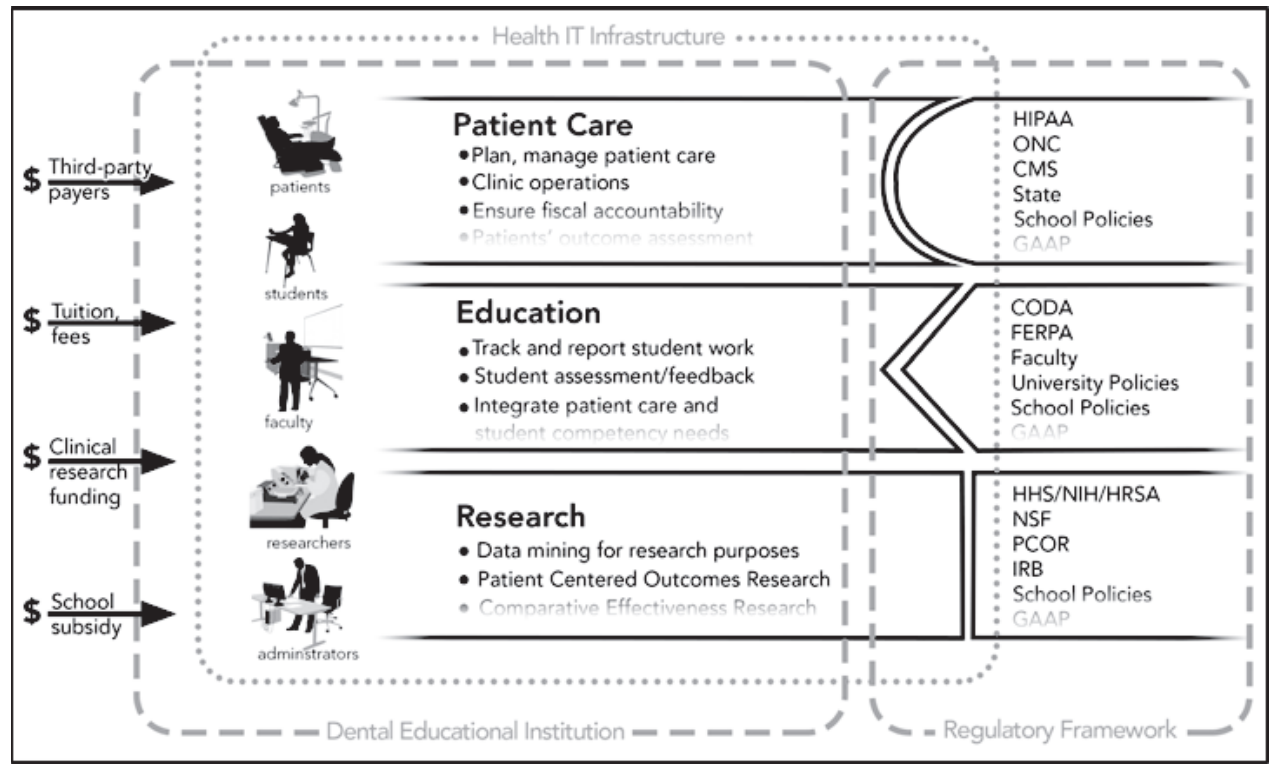

Figure 1. General functions of a dental school Health IT infrastructure and stakeholder composition

HIPAA: Health Insurance Portability and Accountability Act; ONC: Office of the National Coordinator; CMS: Centers for Medicare \& Medicaid Services; GAAP: Generally Accepted Accounting Principles; CODA: Commission on Dental Accreditation; FERPA: Family Educational Rights and Privacy Act; Faculty as example for various university/school policies and procedures; HHS: Department of Health and Human Services; NIH: National Institutes of Health; HRSA: Health Resources and Services Administration; NSF: National Science Foundation; PCOR: patient-centered outcomes research; IRB: Institutional Review Board.

utilize the EHR for traditional core functions, such as scheduling, oral charting, treatment planning, progress notes, billing, student assessment, instrument tracking, etc. One of the schools uses a hybrid electronic/paper solution.) Our goal is not to evaluate products or measure patient care or education outcomes, but to begin to understand the costs of operating an EHR in a dental school—a task that appears straightforward on the surface, but is surprisingly complicated when explored in depth. One of the first decisions schools have had to make was whether to build their own EHR or buy a product developed by a vendor. At the outset of the project, we hypothesized that a vendor product might be less expensive than a product developed in-house. Thus, the selection of two schools with a vendor product and two schools with an in-house-developed product was deliberate. The sizes and budgets of the two schools with homegrown systems (total enrollment 408 and 516; total budget $\$ 35$ million and $\$ 63$ million; total patient visits 54,000 and 115,000 ) represent a mix similar to the two schools with packaged solutions (total enrollment 380 and 645; total budget $\$ 38$ million and $\$ 72$ million; total patient visits 55,000 and 134,000 ).

\section{Build versus Buy: Complexities of Health IT}

A review of the literature reveals a dearth of research into the costs of Health IT in medicine, "represent[ing] a major obstacle for decision makers who need reliable information to guide their decisions about EHR implementation." Information on costs for dental school Health IT is even more scant, ${ }^{9}$ a fact that recently resulted in a call for submissions by the editor of this journal. ${ }^{10}$ While some cost analysis studies can be found in the medical literature, only a couple address the full spectrum of diverse implementation costs, efficiency, and costs of health care. ${ }^{11,12}$

Of special interest to us was a comparison between building one's own product and purchasing a vendor-developed product. Purchasing a commercially available product may be implemented relatively quickly, while in-house-developed products will need to be created over time. ${ }^{13,14}$ On the other hand, an in-house-developed product might better address specific needs of the faculty and students at 
the particular institution by allowing all stakeholders to participate in system design. However, in-housedeveloped software can limit flexibility in the future because it may be heavily customized to specific needs at the time it is designed; commercial software, on the other hand, often has capabilities that can be turned on or off depending upon an institution's needs. While participatory design increases buy-in and eases adoption among the user base, custom software development projects often are in danger of not following established best practices, lack compliance with federal mandates, and cease when senior software developers leave the institution and budgetary constraints do not allow for an immediate substitution in the tight market for qualified senior software developers. A prolonged development time impacts what is generally understood in economics as an opportunity cost..$^{15}$ If a solution is purchased, it presumably will be implemented more quickly, yielding new benefits sooner, such as going paperless, expanding functionality, improving customer service, etc. While the custom solution is being developed and implemented, the forgone benefits that could have been gained with a purchased solution are not realized and therefore carry opportunity costs.

While early-generation dental practice management systems were monolithic and usually provided by one vendor, today's current Health IT systems have an EHR as the core software package; however, the complexity of a school's clinical enterprise requires functions in addition to the EHR. Thus, modern clinical systems are comprised of numerous software packages, each from a different vendor. Digital imaging illustrates this complexity. It is common for a school to have one software package to display and organize digital radiographs, another to capture them, and still another to perform specialized tasks such as cephalometric tracings. Billing provides an additional example of this complexity. While the EHR may store the details required for billing, other systems (usually third-party systems) process the data, send the bill, and collect payments. Interactions with insurance companies and state and federal reimbursement agencies add yet another layer of complexity. To operate the core EHR, it is common for the EHR software to require the purchase of an underlying database, e.g., Oracle or MySQL; and all EHR systems require additional software to perform regular backups of data as well as meet Health Insurance Portability and Accountability Act (HIPAA) requirements such as contingency plans to ensure ongoing operations. Thus, looking solely at the core
EHR system skews any meaningful cost analysis of a school's Health IT infrastructure and operations.

In today's health care environment, the question of whether to implement an EHR or to stay paper-based has become obsolete as insurance claim submission requirements and regulatory mandates make the continuation of a purely paper-based system questionable. The federal government has incentivized the adoption of EHR through legislation, mainly the Health IT for Economic and Clinical Health (HITECH) Act, part of the American Recovery and Reinvestment Act of $2009,{ }^{7}$ providing incentives up to a maximum of $\$ 63,750$ over six years to dentists accepting qualifying amounts of Medicaid who meet the eligibility requirements and adopt, implement, or upgrade a certified EHR. In addition, disincentives for not adopting EHR have been built into the legislation, reducing payments by 1 percent in 2015, 2 percent in 2016, and 3 percent in 2017. Adoption in dentistry is widespread, with 94 percent of all U.S. dentists having a computer in their offices ${ }^{16}$ and practically all dental schools using an EHR system.

Attaching a cost measure to the quality of care is a complicated task to begin with, but is rendered even harder as quality assessment in dental care is in a relatively primitive state due to the historical development of our profession, diverse evaluation methods in dental education, the absence of highlevel evidence for many dental treatments, and the fact that there is almost no use of diagnostic codes among practicing dentists. ${ }^{17}$ However, there is a growing trend towards the development of diagnostic terminologies and their implementation by a few dental schools. ${ }^{18,19}$

There seems to be sufficient evidence that we are only at the beginning stages of building a Health IT infrastructure that improves health care. ${ }^{20}$ The potential to pool patient data is enormous and will allow us one day to detect even rare occurrences of diseases, but at this point we are only starting to assemble large oral health databases for clinical research. ${ }^{21} \mathrm{We}$ envision that the goal of a comprehensive Health IT infrastructure to support clinicians and not get in the way of patient care will be achieved, but at a cost. Interoperability, the emergence of personal health records, the growth of evidence-based clinical decision support systems, and enhanced digitization of humans in the area of personalized medicine will allow us to exploit the full potential of Health IT; however, they will do so only at an increased cost. We need to fully understand the costs of current systems so that we can anticipate and possibly forecast future costs. As David 
Blumenthal noted, "Information is the lifeblood of modern medicine, and health information is destined to be its circulatory system." 22

\section{Methods}

This section describes how raw data were collected, summary tables were compiled, and inclusion and exclusion criteria were used to delineate Health IT costs as separate from non-Health IT costs. The cost information presented was derived from the participating institutions' financial records and best estimates if specific information was not available, particularly when a significant amount of time had elapsed since the cost was incurred or it was not tracked. Cost categories were selected and defined to optimize consistency and comparability between institutions despite varying operations and reporting practices.

The University at Buffalo and University of North Carolina at Chapel Hill were combined into the "Custom EHR" group, and the University of Michigan and University of Pittsburgh were combined into the "Purchased EHR" group. Contractual agreements with the vendors in the purchased EHR group prevent disclosure of actual costs to each institution of their respective EHR. Thus, to comply with these agreements, reported costs are averaged within each group, and it is our opinion that averaging does not materially impact the result. If readers have questions about a particular institution, we are open to informal individual conversations about the information and results.

The cost analysis is structured into two major types: 1) initial solution acquisition, and 2) ongoing operations costs. The initial solution acquisition costs include items like the initial license fees/system development, development of initial reports, server software, hardware purchases, start-up training, and data center setup. The ongoing operations costs cover ongoing training and maintenance, training for new employees, infrastructure and point of care hardware, support staff, system development, and ongoing customization to create new reports and adjustments based on the toolkit character of some applications as well as ongoing software costs, including licensing, maintenance, and development. Initial acquisition costs of purchased solutions include software licensing of the EHR and any associated modules, startup hardware and software, technical staff, consulting, training, and project management costs. Recurring costs are based on 2012 actual costs from each institution's financial records and estimates of the amount of individual time spent supporting the EHR and EHR customers utilizing the system from actual and budget reports. Initial acquisition costs, though spread over many years, are not adjusted to reflect the time value of money, but still demonstrate an order of magnitude difference between the costs of building versus purchasing a system. Ongoing costs are as of 2012 .

\section{Results}

Our analysis showed that the cost of creating (\$2.5 million) and sustaining $(\$ 174,000)$ custom EHR software was significantly higher than acquiring $(\$ 500,000)$ and sustaining $(\$ 121,000)$ purchased software. Hardware costs were very similar under both models at $\$ 243,000$ versus $\$ 263,000$ for custom and purchased EHR systems, respectively, with all four institutions employing the same on-site client server hosting model, reflective of solution architecture. Custom support staff cost $(\$ 215,000)$ was 46 percent of reported support staff cost of the purchased solution. Overall, the cost of creating a custom EHR solution was five times greater than a purchased solution, and ongoing support of a custom solution was 74 percent of a purchased solution (Table 1).

\section{Discussion}

We are aware that the results presented here will be met with skepticism and might as a whole have limited applicability for some institutions. However, our goal in presenting the data in the format we have chosen is to empower school administrators to understand the complete financial impact and use it as a point of reference when comparing costs or making estimates for their school. Let data storage serve as an example. Does the EHR proposal include both data storage and backup media? A dental school might decide to select a more expensive central resource provided by the host institution in order to demonstrate good citizenship and strengthen its relationship to the institution at large. In any event, the data storage plan must include a back-up service as well. We also hope that these results will help administrators to secure EHR Incentive Program funds (www. cms.gov/Regulations-and-Guidance/Legislation/ EHRIncentivePrograms/index.html) to offset some of the costs, i.e., a reduction in expense as well as to determine technology fees for students. 
Table 1. High-level EHR cost schedule: custom versus purchased options

\begin{tabular}{|c|c|c|c|c|c|}
\hline \multirow[b]{2}{*}{ Cost Element } & \multicolumn{2}{|c|}{ Custom } & \multicolumn{2}{|c|}{ Purchased } & \multirow{2}{*}{$\frac{\text { Difference }}{\text { Cost }}$} \\
\hline & Cost & & Cost & & \\
\hline $\begin{array}{l}\text { Initial acquisition } \\
\text { Core clinic system } \\
\text { Add-on components }\end{array}$ & $\$ 2,503,971$ & & $\$ 524,523$ & & $\$ 1,979,448$ \\
\hline Ongoing operations* & & $\%$ of Total & & $\%$ of Total & \\
\hline \multicolumn{6}{|l|}{$\begin{array}{l}\text { Software: ongoing maintenance } \\
\text { and support }\end{array}$} \\
\hline Core clinic system & 159,059 & $25 \%$ & 72,617 & $9 \%$ & 86,442 \\
\hline Add-on components & 15,000 & $2 \%$ & 48,434 & $10 \%$ & $(33,434)$ \\
\hline Subtotal software & 174,059 & $28 \%$ & 121,051 & $18 \%$ & 53,008 \\
\hline \multicolumn{6}{|l|}{ Hardware } \\
\hline Server infrastructure & 88,850 & $14 \%$ & 88,047 & $4 \%$ & 803 \\
\hline Point of care & 153,770 & $24 \%$ & 174,750 & $15 \%$ & $(20,980)$ \\
\hline Subtotal hardware & 242,620 & $38 \%$ & 262,797 & $19 \%$ & $(20,177)$ \\
\hline \multicolumn{6}{|l|}{ Support staff } \\
\hline $\begin{array}{l}\text { Backend operations (server, } \\
\text { network, etc.) }\end{array}$ & 29,608 & $5 \%$ & 139,071 & $20 \%$ & $(109,463)$ \\
\hline Point of care/customers & 145,529 & $23 \%$ & 232,400 & $29 \%$ & $(86,871)$ \\
\hline Training & 0 & 0 & 22,143 & $3 \%$ & $(22,143)$ \\
\hline Reporting/analysis & 40,000 & $6 \%$ & 20,643 & $5 \%$ & 19,357 \\
\hline Records management & 0 & 0 & 50,000 & $7 \%$ & $(50,000)$ \\
\hline Subtotal support staff & 215,137 & $34 \%$ & 464,257 & $63 \%$ & $(249,120)$ \\
\hline Total ongoing operations & 631,816 & $100 \%$ & 848,105 & $100 \%$ & $(216,289)$ \\
\hline
\end{tabular}

\section{Impact of Culture on Cost}

Our reported historical cost data should not be regarded as a gold standard or even as a rough guideline for what the optimum EHR investment should be. For example, ongoing support staff costs are responsible for the largest variation in ongoing operating costs. Should the custom solution institutions spend more on support and training? (The differences in these cost elements between the two models are due to school priorities and need.) Are the purchased solutions spending too much on those elements? Are those spending levels appropriate in each case because they are driven by the underlying characteristics of the respective solutions?

These questions become all the more important when considering vendor-hosted products. ${ }^{23}$ Institutional requirements for vendor-hosted products are more likely to articulate optimum levels of support, control, availability, backup, recovery, etc. and potentially result in higher costs. When the vendor costs are compared to historical, school-provided service costs, it will be especially important to compare current institution-provided versus vendor-required service and risk levels. A vendor-hosted solution may also appear more expensive because it explicitly gathers the costs together in one bundle, instead of scattering costs across services, each with a different business model. Similar questions arise for solution acquisition. Is it worth the additional investment to have a custom solution that presumably "fits like a glove"? Were the timing and amount of investment driven by availability of funds (either higher or lower) or by optimal investment levels and timing? Would a more concentrated custom investment in a shorter time frame have reduced total cost? Or did the school grow weary of the investment requirements and pull back, when a better decision might have been to increase investment and move more quickly? Are the schools incorrectly influenced by already incurred costs? Did the additional investment competitively differentiate the custom EHR from the purchased 
EHR? Thus, our results reflect what was spent, not what an individual institution should spend.

\section{Implementation Strategy}

A discussion of implementation strategy must not be omitted from the interpretation of our results. The results clearly indicate creation of a custom solution requires significantly more investment than acquiring a purchased solution. Presumably, a school decides to create and continue with a custom solution to achieve benefits not in packaged solutions. It is interesting to consider what portion of a custom solution is actually very similar to a purchased solution, at least to the point of being equally acceptable to a school. In turn, what portion of the solution is truly "custom," providing additional value not found in packaged solutions? Then, what is the true cost of the marginal, value-added customization, and is it worth it? Do schools really need ten different grading methods supported? For example, if one of the custom solution schools said 80 percent of what it has can be found in a packaged solution at a cost of $\$ 500,000$, are the customized elements worth $\$ 2$ million ( $\$ 2.5$ million minus $\$ 0.5$ million)? The same questions apply to purchased systems related to any add-on modules, customizations, and shadow systems. Does the marginal cost of those elements support the marginal benefits gained?

\section{Is Uniqueness Worth the Cost?}

It is not surprising that the custom solution costs more to create and maintain than the purchased solution. The custom solution has one customer who pays the entire cost, whereas the purchased solution has many customers who share the cost. The purchased solution limits the ability of one customer to influence product direction, but the purchased solution also benefits from the influence and domain knowledge of many customers. As vendor-hosted solutions, also known as cloud solutions, become more prevalent, these trade-offs will extend more deeply into ongoing operating costs as hardware, backup and recovery, software updating, and some support shift to the vendor. Together, the costs, benefits, and trade-offs raise core underlying questions about what the school's mission is and if that mission is served by providing some or all of these IT functions. A school may decide to spend more on an outside provider so it can better focus on its core mission, or it may decide to spend more internally because its leaders feel it will better enable the school to be true to its overall mission.

Again, the culture of the institution determines how far the conversation can be shifted from the uniqueness of certain areas towards a discussion about similarities among areas-with uniqueness being more expensive in the short and long run. A school that develops its own EHR could get trapped in its current approach because of already-invested costs. Is it more difficult for an institution that has invested $\$ 2.5$ million in a custom solution to objectively evaluate custom versus purchased options and decide to switch than, say, for a brand new dental school to evaluate those options? If it is hard to imagine a new dental school deciding to build a clinic management system from scratch, does that have implications for others making the decision? The objective should be to evaluate the additional costs and benefits of an alternative going forward without consideration of past investment. Past investment has been spent: water under the proverbial bridge.

\section{Risk}

Woven throughout the comparison of cost and analysis of alternatives is the institution's stated and actual risk profile with regards to regulatory compliance, contingency planning, system reliability, etc. How much risk is the institution willing to take in these areas? How much risk is it actually taking? Have budget reductions and investment decisions eroded actual backup and recovery, staff training, system functionality, security, etc. over time so more is incurred than perceived or desired? If this is the case, does it distort cost comparison between internal and vendor costs when vendors quote costs consistent with stated requirements that may be more consistent with the desired risk profile? What are the staffing risks if key staff members leave? Note that these questions apply to both custom and purchased solutions equally, though they may manifest to different degrees. It could be that vendor-hosted solutions would be riskier because the institution does do a good job managing and mitigating risk consistent with stated objectives. These questions are meant to be issues that each institution needs to consider. They are not intended to lead to conclusions in themselves.

Delineation of costs and understanding their drivers for one's own institution and others assist in evaluating directions and alternatives. Evaluation of alternatives should include a review of their impact in each of the initial and ongoing cost areas. Whether 
institution-developed or vendor-developed, what is the impact on server and point of care hardware?

\section{Limitations}

We are aware that our methodology has inherent limitations due to the complexity of the costs associated with a distributed system like an EHR. Lacking a recognized validated instrument or established method for calculating dental education EHR costs, a description of how the data were compiled is provided, allowing readers to draw their own conclusions based on the historical data.

Identification of actual costs is problematic depending on the degree to which EHR-related services are managed centrally at an institution versus within the dental school and the cost-sharing policies employed for these services and pooled resources, such as network costs, central IT support, or software license costs. This study made best estimates of what actual EHR costs were, based on whether they were directly related to provision of the EHR not on who funded or paid for those costs.

While the analysis is structured into initial solution acquisition and ongoing operations costs, this division in itself might be flawed because each school developed and executed its implementation differently. For example, the University of Michigan first implemented the scheduling and financial portions of its purchased EHR and then, due to special requirements of each clinic, added the EHR to its twenty-five clinics over the course of several years. The University of Pittsburgh, on the other hand, completed the entire rollout in eighteen months. Reporting of initial acquisition costs is particularly difficult for custom-built EHRs because "acquisition" occurs over many years, blurred by an ever-changing mix of "new" development and ongoing maintenance, and initial development costs were not tracked as such. Custom EHR initial acquisition costs include developer, network/server staff, and IT leadership expenses adjusted for best estimates of each year's new development versus ongoing maintenance mix since inception, with the goal of including only estimated new development cost. Time spent by non-technical faculty and staff contributing to requirements, specifications, testing, and implementation is not included because a reasonable way to arrive at the estimated cost is not available due to the passage of time.

Discussion of financial gains due to the EHR, such as increases in collections due to more timely and accurate transactions data, is omitted as beyond the scope of this study. Private practices and hos- pitals have experienced an increase in billing and collection after implementing an EHR, ${ }^{24,25}$ and some have even associated the EHR and their associated costs of creation, installation, and operation with contributing to the explosion of health care costs in the United States. ${ }^{26}$

The expected life cycle of any major electronic system is typically not more than ten years. After that, timeframe systems usually need to be redesigned from scratch as technology and platforms have changed dramatically and may not support the initially chosen architecture. For schools using a commercial client-server system, this means a dependence on the vendor to commit investment to evolving technologies instead of stagnation. For schools using a home-grown system, it means the institution needs to plan for a major future investment in labor, hiring programmers who work on the new system for years without supporting the current installation. And for schools using a cloud-based system, it could mean relying on the vendor or user community to trigger such development cycles and upgrade systems without service interruption.

\section{Conclusion}

Information technology decision making is often described and guided by three main categories: 1) foundational services, which are treated like a utility as they must be ubiquitously available; examples are network connections, storage, and backup services; 2) mission-unique services, which differ from area to area and include special hardware like viewing stations for radiology departments or access to patients' billing data by the financial group; and 3) innovation services, which are emerging technologies that are tested for feasibility and explored for their potential to be widely deployed. While dental schools have a responsibility to patients and students to operate securely and safely in providing continuity of care and delivering a high-quality educational experience, we in academia have an obligation to work in the last category - innovation services - in order to explore new frontiers and evaluate their merit and worth. This obligation clearly distinguishes an academic dental institution from a private practice of similar size or patient volume whose operations strive for stability and are limited to the adoption of proven and tested technologies.

We need to consider the increasing commoditization of $\mathrm{IT}^{27}$ - a process that has been compared 
with the widespread availability of electrical power or general transportation in earlier times. While there are seemingly unlimited possibilities in the use of IT in health care and elsewhere, we must not fall into the trap of the overinvestment in railroads in the 1860s. Strategic value is born out of uniqueness and scarcity and not out of ubiquity. ${ }^{27}$ For academic dental institutions, this means we no longer advertise the existence of electrical power and wireless access in lecture halls and operatories or that we are located near a railroad station or an airport - obviously. Are we at the brink of stopping to advertise that we use an EHR? That might turn out to be the wrong question as the EHR is at the core of our institutions' mission (see Figure 1). The question should rather be how do we use our Health IT infrastructure with the EHR at its core to support a research agenda that covers the full spectrum of scholarship to improve health, basic research, implementation and dissemination research, clinical efficacy and effectiveness research, community and population research, and dental education research. ${ }^{28}$

In our view, such lofty goals can only be achieved if we free up our IT support staff from mundane maintenance tasks, like patching our servers' operating system, backing up data and carrying tapes to an offsite storage location, patching EHR software, writing custom reports for data that should be available upon installation, and securing servers against malicious attacks. If we go this route, the savings might not immediately translate into dollar amounts since institutions' IT groups are often understaffed and overworked. Thus, staff members might not be released, but might finally have the time available to shift their attention to value-added tasks supporting the mission of our institutions, like supporting data mining for outcomes research or compiling reports for global assessment and curriculum outcomes. In addition, we would like to note that in some instances internal IT units may have had to cut corners to fulfill institutional demands, consequently exposing the institution to risks, e.g., not running a redundant recovery system at an external location to maintain a 99.9 percent uptime capability. Transferring such tasks to a vendor who is fully responsible through contractual agreements might in some instances result in increased costs, but at the same time in lower exposure risk to the institution. It is worthwhile to note that costs for the entire Health IT infrastructure, not just the license costs for the EHR software, should be better tracked by schools to make cost analyses like this one easier to perform and therefore provide a readily accessible decision support tool for administrators.

Outsourcing services has received a bad reputation in the United States as it is often associated with shifting jobs overseas. However, outsourcing inside one's own institution might be a first step towards treating Health IT as a commodity. For instance, instead of maintaining a dental school data center, servers can often be hosted at the larger institution's network operating center (NOC). Using shared services allows dental schools to benefit from the economy of scale - though we acknowledge that some academic dental institutions do not belong to a university or other larger institution and would have to purchase expensive commercial services and that some larger institutions run NOCs that are not HIPAA-compliant.

Taking the next step brings us to cloud-based systems, such as using an EHR under the Software as a Service (SaaS) model. Using this new software paradigm allows academic dental institutions to tap into the advantages associated with cloud-based technology, among them the handing off of all maintenance tasks associated with an EHR, such as patching and upgrades. If the model is expanded to an Infrastructure as a Service (IaaS), data storage and backup can be delegated as well, which frees up institutional resources and is often associated with a great reduction of costs. Fears about losing control of data and processes are justified, but can be dealt with using mechanisms such as Business Associates Agreements, HIPAA audits, and community oversight. Community oversight can be achieved through collaborative organizations, such as Internet2 (www.internet2.edu/), a member-owned advanced technology community founded by the nation's leading higher education institutions in 1996. Internet2, consisting of 220 U.S. universities, sixty leading corporations, and seventy government agencies, provides a collaborative environment for U.S. research and education organizations to solve common technology challenges and to develop innovative solutions in support of their educational, research, and community service missions. Given the life cycle of applications, SaaS usually becomes more expensive after five to seven years, ${ }^{29}$ when license costs are compared to on-site installations. However, usually a major overhaul of the software application or the purchase of a new system would be planned anyway after that timeframe.

It is critical that such Health IT decisions are made in accordance with a governance process that 
informs and advises: without a good process, acceptance will be difficult as each outsourcing is inevitably associated with a reduction of control. Reduced control might result, for instance, in planned service interruptions due to upgrades at times that disrupt important events, e.g., EHR not available during board exams. Such considerations must be in alignment with the culture of the institution as well as call for coordination with the institution's chief information officer. Navigating this complicated environment requires knowledgeable leaders, like trained informaticians who understand and are experienced in the education, patient care, and research missions. These leaders must be supported by an advisory committee that serves as a liaison between the clinical educators and the IT experts.

There is much lamenting about current challenges in higher education driven by reduced state funding and cuts in federal research funding. However, we see these challenges as opportunities, motivating us to engage in a comprehensive rethinking of existing processes and established procedures. For dental schools, further study and reflection on Health IT should be part of that.

\section{Acknowledgments}

The authors could not have completed their analysis without the help and support of institutional support staff members, such as Dr. Fen Zheng, IT Manager, and Ms. Kelly Coldwell, Business Staff (both University of Pittsburgh School of Dental Medicine), and Ms. Diana Blackford, Administrative Specialist, Office of Dental Informatics (University of Michigan). Special thanks go to Mr. Mike Guay, Analyst at Midwest Education, Gartner, Inc. The authors would like to express their gratitude to our pre-submission reviewers, who significantly shaped our thinking and improved the manuscript: Dr. Cecile Feldman, Dean, Rutgers School of Dental Medicine, and Dr. Gary Guest, Associate Dean for Patient Care, University of Texas Health Science Center at San Antonio Dental School. For preparing the manuscript and bibliography for submission, the authors wish to thank Michael Dziabiak. The thoughtful comments and suggestions provided by the anonymous reviewers elevated our initial manuscript to a new level; we would like to express our gratitude for their contributions. Special thanks go to all dental school IT staff who work hard every day to provide the stable technology services that keep our schools' critical operations working 365 days a year.

\section{REFERENCES}

1. Mieritz L, Kirwin B. Defining Gartner total cost of ownership. Stamford, CT: Gartner, 2005.

2. Hillestad R, Bigelow J, Bower A, et al. Can electronic medical record systems transform health care? Potential health benefits, savings, and costs. Health Aff(Millwood) 2005;24(5):1103-17.

3. Parente ST, McCullough JS. Health information technology and patient safety: evidence from panel data. Health Aff (Millwood) 2009;28(2):357-60.

4. Rand Coporation. Electronic medical records not always linked to better care in hospitals. December 2010. At: www.rand.org/news/press/2010/12/23.html. Accessed: September 9, 2013.

5. Atkinson JC, Zeller GG, Shah C. Electronic patient records for dental school clinics: more than paperless systems. J Dent Educ 2002;66(5):634-42.

6. Patient protection and affordable care act of 2010, Pub. L. 11-148, 119-124 Stat. 1025 (Mar. 10, 2010).

7. The American recovery and reinvestment act of 2009 (ARRA): health information technology for economic and clinical health act (HITECH Act) of 2009, Public Law 111-5, 123 Stat 115 (Feb. 17, 2009).

8. Gallego AI, Gagnon MP, Desmartis M. Assessing the cost of electronic health records: a review of cost indicators. Telemed J E Health 2010;16(9):963-72.

9. Langabeer JR, Walji MF, Taylor D, Valenza JA. Economic outcomes of a dental electronic patient record. J Dent Educ 2008;72(10):1189-200.

10. Karimbux NY. Costs and benefits of an electronic health record (editor's note). J Dent Educ 2013;77(4):391.

11. Chaudhry B, Wang J, Wu S, et al. Systematic review: impact of health information technology on quality, efficiency, and costs of medical care. Ann Intern Med 2006;144(10):742-52.

12. Delpierre C, Cuzin L, Fillaux J, et al. A systematic review of computer-based patient record systems and quality of care: more randomized clinical trials or a broader approach? Int J Qual Health Care 2004;16(5):407-16.

13. Bates DW. Invited commentary: the road to implementation of the electronic health record. Proc (Bayl Univ Med Cent) 2006;19(4):311-2.

14. Shekelle PG, Morton SC, Keeler EB. Costs and benefits of health information technology. Evid Rep Technol Assess (Full Rep) 2006;132:1-71.

15. Buchanan JM. Opportunity cost. In: Durlauf SN, Blume LE, eds. The Palgrave dictionary of economics. 2nd ed. New York: Palgrave Macmillan, 2008.

16. American Dental Association, Survey Center. 2010 technology and social media survey. Chicago: American Dental Association, 2012.

17. Bader JD. Challenges in quality assessment of dental care. J Am Dent Assoc 2009;140:1456-64.

18. Tokede O, White J, Stark PC, et al. Assessing use of a standardized dental diagnostic terminology in an electronic health record. J Dent Educ 2013;77(1):24-36.

19. Kalenderian E, Ramoni RL, White JM, et al. The development of a dental diagnostic terminology. J Dent Educ 2011;75(1):68-76. 
20. Topol E. The creative destruction of medicine: how the digital revolution will create better health care. New York: Basic Books, 2012.

21. Walji MF, Tran A, Kalenderian E, et al. Development of an oral health research repository using i2b2. J Dent Educ 2010;74(2):223(Abstract).

22. Blumenthal D. Launching HITECH. N Engl J Med 2010;362(5):382-5.

23. Internet2: ICE health systems. 2013. At: www.internet2. edu/products-services/cloud-services-applications/icehealth-systems/. Accessed: November 25, 2013.

24. Adler-Milstein J, Green CE, Bates DW. A survey analysis suggests that electronic health records will yield revenue gains for some practices and losses for many. Health Aff (Millwood) 2013;32(3):562-70.
25. Samaan ZM, Klein MD, Mansour ME, DeWitt TG. The impact of the electronic health record on an academic pediatric primary care center. J Ambul Care Manage 2009;32(3):180-7.

26. Baldwin G. The $\$ 80$ billion question: can EHRs curtail runaway costs? The government is betting yes, but the economic calculations are tangled. Health Data Manag 2011;19(6):24

27. Carr NG. IT doesn't matter. Harvard Business Rev 2003;81(5):41-9.

28. Bonham AC, Solomon MZ. Moving comparative effectiveness research into practice: implementation of science and the role of academic medicine. Health Aff(Millwood) 2010;29(10):1901-5.

29. Personal communication, Michael Guay, Analyst at Midwest Education, Gartner, Inc., March 2013. 